Dermatology 2016;232:83-85

DOI: $10.1159 / 000435914$

\section{Signet Ring-Like Cells: A New Reflectance Confocal Microscopy Clue of Interface Dermatitis Correlated to Basal Cell Vacuolization in Histopathology}

Mona Amini-Adle a , Sébastien Debarbieuxa ${ }^{\mathrm{a}}$, Marie Perier-Muzet ${ }^{\mathrm{a}}$, Brigitte Balme ${ }^{\mathrm{b}}$, Stéphane Dalle ${ }^{\mathrm{a}}$, Luc Thomas ${ }^{\mathrm{a}}$

a Department of Dermatology, Lyon 1 University, and ${ }^{b}$ Department of Anatomopathology, Centre Hospitalier Lyon Sud, Pierre-Bénite, France

\section{Key Words}

Interface dermatitis $\cdot$ Signet ring cell $\cdot$ Reflectance confocal microscopy

Interface dermatitis refers to a group of disorders which include characteristic histopathological findings involving the dermoepidermal junction (DEJ). Basal cell vacuolization, apoptotic keratinocytes and obscuring of the DEJ by inflammatory cells are the hallmark of primary changes found in this entity. Lupus erythematosus, lichen planus, dermatomyositis, graft versus host disease, erythema multiforme, fixed drug eruptions, lichen striatus, and pityriasis lichenoides are considered as major interface diseases [1]. Little literature is available regarding the in vivo reflectance confocal microscopy (RCM) features of interface dermatitis. To date, two pilot studies have focused on the RCM criteria of lichen planus [2] and discoid lupus erythematosus [3]. Interface changes have mainly been described in terms of architectural alteration of the DEJ. Although the loss of ring-like structures around dermal papillae and the presence of mildly refractile cells at the DEJ have been highlighted in both studies, the morphological alterations of the histopathologically so-called 'vacuolated basal cells' have not been specifically described. We repeatedly observed a previously unreported RCM appearance of basal cells in 5 cases of interface dermatitis, including 2 lichen planus (fig. 1d, e), 1 lichenoid skin drug eruption (fig. 1f), 1 disseminated lupus erythematosus (fig. 2b), and 1 dermatomyositis (fig. 2e) character- ized by a signet ring aspect. 'RCM signet ring-like cells' correspond to a complete annular bright ring with a polar reinforcement, surrounding a dark center. This aspect brings to mind the eccentric pyknotic nucleus encompassed by a vacuolized cytoplasm (appearing as a dark center) seen on the histopathological examination of a skin biopsy performed immediately after RCM on the very same area in 4 cases (fig. 1g, h, 2c, f) - in 1 case, the biopsy had been performed before RCM (fig. 1i). We observed a higher number of signet ring-like cells with RCM images compared to the histopathological sections. This could be related to the en face horizontal view given by RCM. Keratinocyte necrosis and apoptotic keratinocytes are considered to be responsible for the vacuolar degeneration of the DEJ seen in interface dermatitis [4]. Intraepidermal necrotic keratinocytes have been described with RCM in lichen planus [2] and lupus erythematosus [3] as mildly bright, polygonal structures larger than surrounding keratinocytes. However, the cellular changes we observed at the DEJ, and which we correlated to basal cell vacuolization, have not been described in these previous pilot studies. We believe it is worth emphasizing this morphological alteration, which could represent an additional clue for the RCM diagnosis of interface dermatitis and which deserves to be confirmed by complementary studies.

Disclosure Statement

The authors declare no conflict of interests.

\section{References}

1 Joshi R: Interface dermatitis. Indian J Dermatol Venereol Leprol 2013; 79:349-359.

-2 Moscarella E, González S, Agozzino M, Sánchez-Mateos JL, Panetta C, Contaldo M, Ardigò M: Pilot study on reflectance confocal microscopy imaging of lichen planus: a real-time, non-invasive aid for clinical diagnosis. J Eur Acad Dermatol Venereol 2012;26:1258-1265.

- 3 Ardigò M, Maliszewski I, Cota C, Scope A, Sacerdoti G, Gonzalez S, Berardesca E: Preliminary evaluation of in vivo reflectance confocal microscopy features of discoid lupus erythematosus. Br J Dermatol 2007; 156:1196-1203.

4 Sontheimer RD: Lichenoid tissue reaction/interface dermatitis: clinical and histological perspectives. J Invest Dermatol 2009;129:1088-1099.

\section{KARGER}

E-Mail karger@karger.com www.karger.com/drm (c) 2015 S. Karger AG, Base

$1018-8665 / 15 / 2321-0083 \$ 39.50 / 0$
Dr. Sébastien Debarbieux

Department of Dermatology, Lyon 1 University, Centre Hospitalier Lyon Sud Chemin du grand Revoyet

FR-69495 Pierre-Bénite Cedex (France)

E-Mail sebastien.debarbieux@chu-lyon.fr 

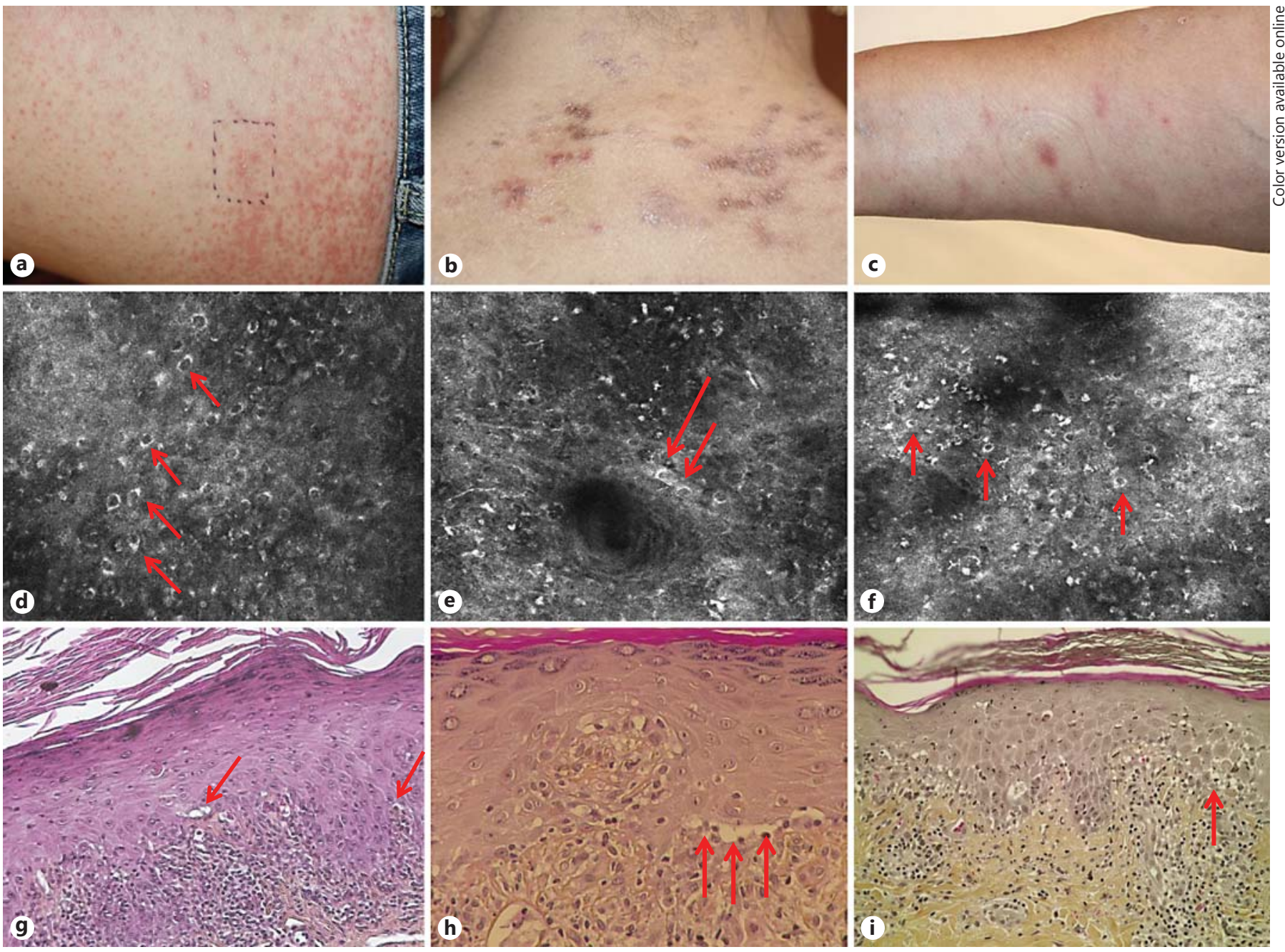

Fig. 1. a, b Clinical aspect of lichen planus in a 45-year-old female (patient 1) and a 64-year-old female (patient 2), respectively. c Clinical aspect of a lichenoid drug eruption in a 70-year-old female (patient 3). d-f RCM images of the DEJ demonstrating the presence of signet ring-like cells (red arrows; color in online version only) with a refractive ring and a reinforcement in a pole and a dark center corresponding to the vacuolized cytoplasm; images

of patients 1, 2 and 3, respectively. g-i Histopathological section stained with $\mathrm{HE}$ and showing basal cell vacuolization and bandlike cell infiltrate at the DEJ. Red arrows correspond to the vacuolized basal cell with eccentric nucleus encompassed by a dilated cytoplasm. Histopathological sections of patients 1, 2 and 3, respectively. HE. $\times 40$. 

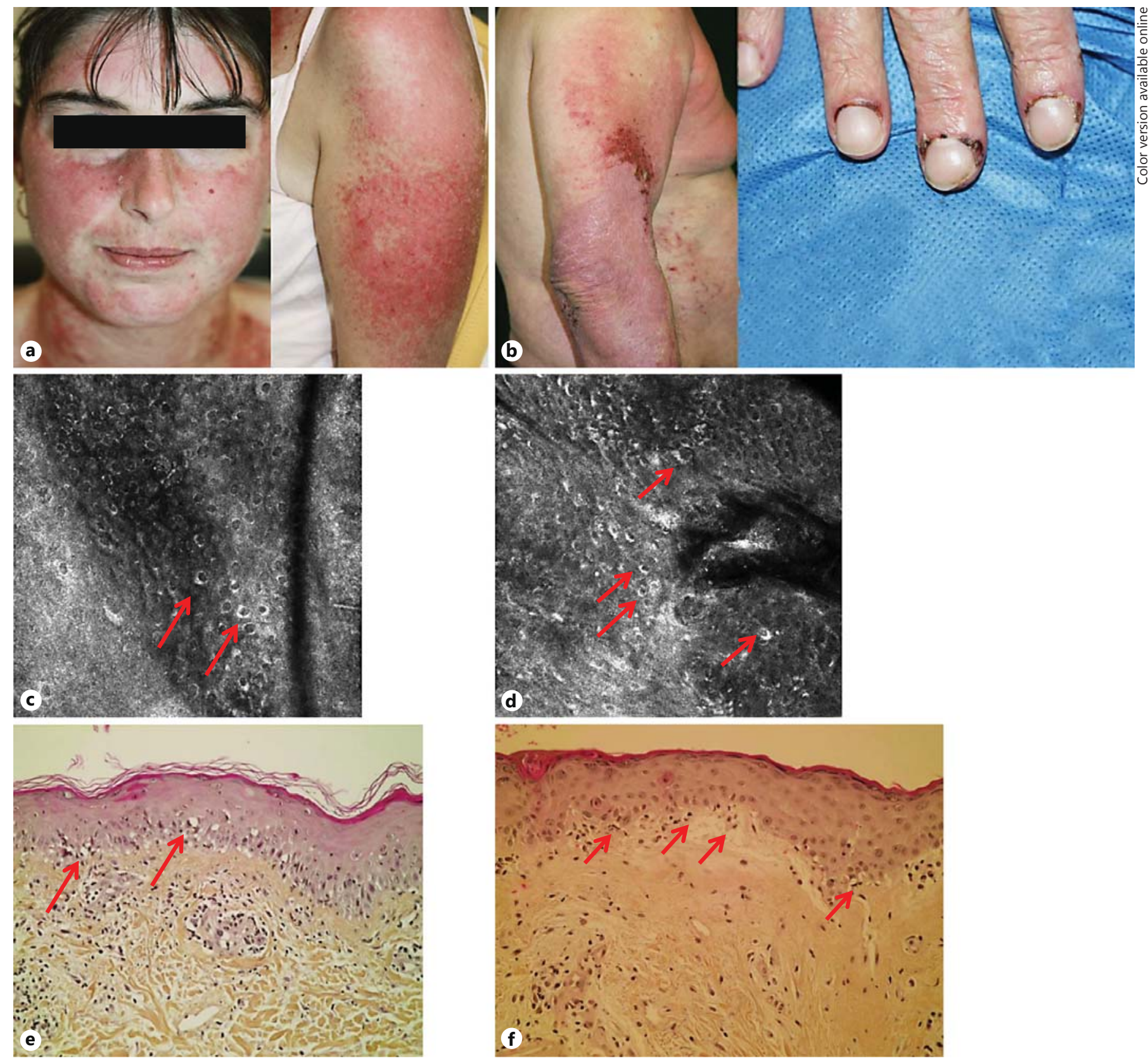

Fig. 2. a A 34-year-old female with disseminated lupus erythematosus (patient 4). b Clinical picture of dermatomyositis in a 70-year-old male (patient 5). c, d RCM images demonstrate a similar aspect at the DEJ with the presence of signet ring-like cells. e, $\mathbf{f}$ HE-stained slides showing histopathological aspect of patients 4 and 5, respectively, with typical interface dermatitis changes including basal cell vacuolization and band-like inflammatory infiltrate at the DEJ. HE. $\times 20$. 